\title{
La lucha contra el olvido de las Madres de "Falsos Positivos" de Soacha y Bogotá (MAFAPO): condiciones y formas de movilizar una memoria subterránea (2008-2018)
}

\author{
Carlos Arturo Gutiérrez Rodríguez \\ cagutrod@gmail.com \\ Universidad Nacional de La Plata, Argentina
}

Cita sugerida: Gutiérrez Rodríguez, C. A. (2020). [Revisión de Tesis La luch a contra el olvido de las Madres de "Falsos Positivos" de Soacha y Bogotá (MAFAPO): condiciones y formas de movilizar una memoria subterránea (2008-2018)]. Aletheia, 11(21), e080. https://doi.org/10.24215/18533701e080

Defensa de Tesis: 7 de julio de 2020

Director: Dr. Santiago Cueto Rúa

La tensión (porosa, múltiple y siempre inacabada) entre la memoria y el olvido, está mediada por las acciones humanas que destacan ciertos hechos del pasado reciente, con objetivos políticos de cara a nuevas coyunturas. En ese universo, entran en disputa diferentes memorias, que ponen en juego subjetividades, emociones, formas, intereses, narrativas, condiciones sociales y relaciones de poder. La tesis reseñada se ubica en un rincón específico de ese mundo de luchas memoriales. En ella se aborda la lucha de un colectivo de Madres ${ }^{1}$ colombianas: Las Madres de 'Falsos Positivos' (MAFAPO), cuyos hijos fueron asesinados en el marco de una política del Ejército Nacional de Colombia comúnmente conocida bajo el nombre de 'falsos positivos'2.

Este eufemismo es utilizado para referirse al reclutamiento y posterior asesinato de personas que fueron presentadas por el ejército colombiano - con aquiescencia de otras instituciones del Estado y con la participación activa (y casi simbiótica) de grupos paramilitares - como miembros de grupos armados asesinados en combate. A través de esta práctica, que la Corte Penal Internacional (2018) categorizó como un crimen de lesa humanidad en tanto se trató de hechos sistemáticos y generalizados, los soldados recibían beneficios que se traducían en ascensos, dinero y permisos. Al tiempo, se engañaba a la sociedad presentando 
resultados ${ }^{3}$ falsos que querían proyectar la idea de un Estado victorioso que recuperaba los territorios ocupados por grupos armados.

A pesar de que existan registros de este tipo de prácticas por lo menos desde 1984 (Cinep, 2011, p. 14), estas aumentaron significativamente durante los gobiernos de Álvaro Uribe Vélez (2002-2010) y, a pesar de sus enormes esfuerzos para que se olvidaran, se consideran un crimen emblemático entre los cometidos por el Estado en el marco del conflicto armado colombiano.

En la importante visibilidad que alcanzan los hechos, es protagónico el caso de unos muchachos reclutados en Soacha y Bogotá, en el año 2008, para ser asesinados en Ocaña (Norte de Santander) a más de 600 kilómetros de sus hogares. La lucha que familiares de las víctimas adelantaron para esclarecer lo sucedido dio lugar a un grupo bautizado por los medios de comunicación como Las Madres de Soacha. Tiempo después, otras mujeres con familiares asesinados bajo la misma modalidad pero en lugares y momentos distintos, al ver la visibilidad que adquiere el caso en medios de comunicación, deciden contactar al grupo de Soacha y establecer vínculos para luchar colectivamente por verdad, justicia, reparación y garantías de no repetición.

La salida a la luz del caso de Soacha, hizo imposible el olvido pretendido de los 'falsos positivos' y puso en contacto a familiares de los jóvenes asesinados, que, tejiendo vínculos con organizaciones defensoras de derechos humanos, dieron lugar al colectivo estudiado en la tesis.

Ellas movilizan una memoria subterránea (Pollak, 2006) que quiso ser enterrada por el Estado y adelantan una batalla contra el olvido, dando visibilidad a hechos que tenían un espacio de escucha muy limitado y que actualmente cuentan con una visibilidad relevante, a pesar de que siguen siendo negados por algunos sectores, próximos a la extrema derecha, afines a Álvaro Uribe.

El texto de la tesis orbita alrededor de testimonios tomados personalmente a mujeres que integran el colectivo. Tales testimonios se pusieron en diálogo con otro tipo de fuentes documentales, haciendo uso de herramientas propias de la antropología y la historia oral. Las entrevistas fueron de tipo no-estructurado (Pineda y Alvarado, 2008) y pretendían desarrollarse en el tono de una conversación, mediada por la empatía, en medio de la cual pudiera emerger la subjetividad de las entrevistadas.

La escritura de la tesis, como señala el apartado metodológico, hizo manifiesta una serie de tensiones que problematizan la supuesta neutralidad del investigador ante hechos que me interpelaron personal y éticamente. En ella aparecen discusiones propias de análisis en los que se trabaja con personas y no sobre personas, pues no se trata de objetos de estudio inertes.

En ese orden de ideas, la tesis se pregunta por las condiciones y las formas a través de las cuales la memoria de MAFAPO se ha movilizado y se organiza en cinco capítulos: El primero describe con profundidad el contexto en el cual tienen lugar el reclutamiento y asesinato de los familiares de las Madres. Al decantar esas condiciones, el apartado desnuda la memoria hegemónica que ellas enfrentan y analiza los rezagos del discurso de la Guerra Fría de los que se vale esa lectura hegemónica, que también se articuló con el nuevo orden internacional que tiene lugar después del atentado a las torres gemelas del 11 de septiembre de 2001. Esa memoria hegemónica presenta a las fuerzas armadas como las salvadoras de una nación desangrada por el terror y muestra a las guerrillas como a las causantes de todos los males del país.

Como demostraron los testimonios, ese relato fue tan poderoso que incluso filtró a algunas Madres, atravesándolas de tal manera que en su discurso es fundamental desmarcar a sus hijos de la falsa acusación de ser guerrilleros (y el estigma que eso acarrea), a pesar de que, como evidencian otras fuentes documentales, varios de ellos no fueron presentados como insurgentes, sino como integrantes de bandas residuales de los paramilitares.

Precisada la memoria hegemónica, que resulta indispensable en tanto existe una tensión dialéctica con la memoria subterránea de MAFAPO, era necesario reflexionar sobre los espacios de visibilidad que tuvo el relato de las Madres, en un contexto en el que las narrativas que presentan a las fuerzas armadas como victimarias se ven eclipsadas por la propaganda que las exhibe como salvadoras. 
En ese sentido, el segundo capítulo se ocupa de analizar los medios de comunicación en tanto estos funcionan como ese lugar a través del cual adquieren relevancia los 'falsos positivos'. Sin embargo, tal reflexión no se ocupa de analizar en detalle cómo y por qué éste se convierte en un lugar de enunciación privilegiado. En tanto el eje de la tesis son los testimonios, el apartado reflexiona sobre cómo aparecen los medios de comunicación en la memoria de las Madres.

Saldada la necesidad de precisar las condiciones en las que emerge el colectivo, el tercer capítulo explora el cambio en la subjetividad de las integrantes de MAFAPO. Como ellas mismas afirman, antes de ser visitadas personalmente por la muerte de sus familiares (salvo un par de excepciones) el conflicto armado era lejano y las violaciones sistemáticas a los derechos humanos eran una realidad vedada. El apartado se pregunta por el acompañamiento y la importancia que tienen otras organizaciones defensoras de derechos humanos, algunas también integradas por víctimas de procesos de violencia masiva en el marco del conflicto armado, en la constitución del colectivo y en la definición de sus demandas.

Esos reclamos, categorizados en cuatro ítems: Verdad, Justicia, Reparación y Garantías de No Repetición, son analizados con detalle en el cuarto capítulo, que evidencia la relación paradójica y compleja que el colectivo tiene con el Estado: el garante de los derechos los violó, pues los militares asesinaron a sus familiares en representación del mismo. Después de actuar como victimario se desplegaron políticas de reparación que en ocasiones fueron exitosas y otras veces terminaron en re victimizaciones. Con esto en mente, el apartado indaga en las formas a través de las cuales aparece el Estado en su memoria y explora la sensación generalizada de abandono estatal que las Madres comunican. Asimismo se problematiza la creencia, usada frecuentemente en la teoría social, de que el Estado es un ser unificado y con voluntad propia, que actúa como un ente.

El último capítulo investiga, valiéndose del análisis de la acción colectiva, la materialidad que ha adquirido esa memoria subterránea. Un hallazgo de la investigación revela que el arte funciona como un repertorio de acción colectiva contenida, que sirve a la memoria que movilizan como un bastión de resistencia a través del cual es posible dar trámite al dolor y hacer una elaboración del duelo, al tiempo que funciona como un espacio de denuncia para los hechos que las victimizaron. En ese sentido, su memoria se ha movilizado a través de telares, murales, galerías fotográficas, tatuajes y otras expresiones artísticas diversas, que han abierto caminos de reparación y que han contado, además, con la orientación de artistas. A manera de cierre, se ofrecen unas reflexiones sobre los límites que tiene el uso del arte como una forma pública de comunicar las denuncias y también reconoce la dimensión emocional y la potencia política que existe en las fibras emocionales tanto de quienes reciben como de quienes emiten el mensaje.

En suma, la tesis hace un análisis interdisciplinar de la batalla memorial que lleva adelante MAFAPO, en donde a través de los capítulos se hace un recorrido que arranca por el análisis de las condiciones en las que se dan los asesinatos de los jóvenes víctimas de los 'falsos positivos' y se tejen los primeros vínculos entre las mujeres que integrarán el colectivo, en 2008, hasta su consolidación en 2018 a través de su propia personería jurídica. Así las cosas, el primer capítulo expone la memoria hegemónica a la que las Madres hacen frente; el segundo da cuenta de las tensiones que existen entre el colectivo y los medios de comunicación; el tercero reflexiona sobre el cambio en las subjetividades de las mujeres que integran el colectivo en su paso de víctimas a pedagogas de la memoria; el cuarto es una apuesta por precisar los reclamos de MAFAPO frente a un Estado victimario y el quinto presenta las acciones y la materialidad en la lucha del colectivo.

En el análisis, sea por su carácter explicativo o por su potencia narrativa, de manera sutil en el quehacer investigativo se colaron elementos, en principio inusuales a la reflexión histórica, como la risa y la fortuna. La tesis ofrece una historización sobre la lucha de este grupo de mujeres, que contra todo pronóstico ha sabido esgrimir las armas de los débiles ${ }^{4}$. En desarrollo de semejante batalla, las Madres han denunciado un crimen de lesa humanidad, cuya memoria ya no pertenece solo a ellas y que a través de reflexiones académicas, conversatorios, charlas, entrevistas, entre otras, circula y se reproduce en nuevas latitudes. Al dar testimonio de un caso que devino emblemático en términos de las violaciones a derechos humanos cometidas por parte 
de agentes estatales, la lucha contra el olvido de las Madres de 'Falsos Positivos' se ha hecho un lugar en los anales de la historia latinoamericana.

\section{ReFERENCIAS}

CINEP - Centro de Investigación y Educación Popular. (2011). Colombia, deuda con la humanidad 2: 23 años de Falsos Positivos. Bogotá: Códice Ltda.

Corte Penal Internacional. (2018). Informe sobre las actividades de examen preliminar. La Haya: Oficina del Fiscal. Obtenido de https://www.icc-cpi.int/itemsDocuments/2018-otp-rep-PE-Colombia.pdf

Pineda, E., y Albarado, E. (2008). Métodos, técnicas e instrumentos de investigación. En E. Pineda, \& E. Albarado, Metodología de la investigación (págs. 143-167). Washington D.C.: Organización Panamericana de la Salud.

Pollak, M. (2006). Memoria, silencio y olvido. La construcción social de identidades frente a las situaciones límite. La Plata: Al Margen Editorial.

\section{Notas}

1 Aunque ellas se auto identifiquen como madres e incluso utilicen el término para dar nombre al colectivo, éste está integrado por hermanas, tías, primas y sobrinas. El uso de la categoría Madre es intencional y apela al lugar social que tiene la maternidad.

2 Otra manera de referirse a los hechos es como "ejecuciones extrajudiciales", nominación que se ajusta al derecho internacional pero es problemática para el caso colombiano en la medida en que la Constitución prohíbe expresamente la pena de muerte. En ese sentido, si no existen las ejecuciones judiciales no es preciso hablar de ejecuciones extrajudiciales. Se utiliza la expresión 'falsos positivos', en tanto ella es usada por MAFAPO.

3 Este concepto se usa en el marco del conteo de cuerpos, una lógica de guerra utilizada por el Estado colombiano en la que se miden los avances de las confrontaciones de acuerdo a la cantidad de adversarios asesinados.

4 Esta expresión surge en la defensa de la tesis y fue dicha por Laura Lenci, una de las evaluadoras. 